Foreign Language Resource Center A Step Forward

John A. Rallo

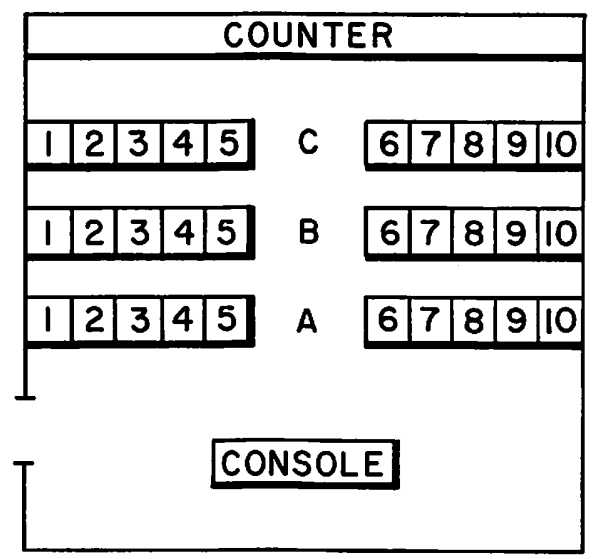

Original Language Lab

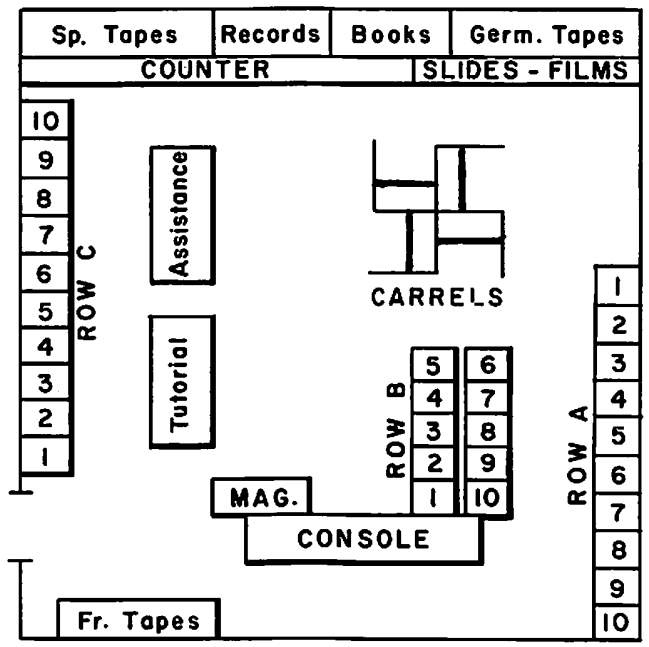

Foreign Language Resource Center 
As trends in education point to the need for more flexible scheduling and independent study programs, it is imperative that administrators and teachers explore new ways to widen the scope of classroom teaching. It is also imperative that they give special consideration to the individual learning process and independent efforts of students. Modern methods of teaching and the availability of instructional materials for use in foreign language laboratories require wiser use of unstructured school time.

The positive and negative aspects of the foreign language laboratory in the total educational process have been frequently analyzed and discussed. Teachers, however, still face the problem of determining the best ways of fulfilling the objectives which have been set up in foreign language programs.

A decade or so ago, when the foreign language laboratory was introduced on a large scale, many educators were of the opinion that this electronic device would help solve the problem of endless, monotonous drills. It was hoped that the laboratory, when properly used, would supplement the classroom work by relegating tedious, repetitive exercises to taped, authentic voices.

This hope, however, was to be only partially fulfilled. The agony suffered by many a teacher who was thrust into a technological venture for which he had neither love nor adequate preparation brought about serious negative results. Today, in many a school, laboratories are being ill-used, discarded, routinized or dismantled. Teachers are frustrated; they are uncertain as to what direction to take.

The Foreign Language Department of Darien High School, too, was faced with this dilemma: to abandon the laboratory, to de-emphasize its importance or to give it a new dimension. We opted for the latter and in the summer of 1968 fundamental changes were made to convert into a FOREIGN LANGUAGE RESOURCE CENTER the original lab (now considered almost obsolete), which had been installed in 1960. The conversion was based, to a large extent, upon the following pedagogical considerations:

I. Utilization of lab during unstructured time.

II. Inter-relationship between classroom and laboratory.

III. Space facilities.

IV. Operational Procedures.

V. Objectives. 


\section{A Step Forward}

VI. Use of Center.

VII. Supervision.

VIII. Teacher release time and tutorial assistance.

IX. Provision for visual materials emphasizing cultural aspects.

$\mathrm{X}$. Reading.

\section{UTILIZATION OF LAB DURING UNSTRUCTURED TIME}

Originally, the lab had been used by students for one scheduled period per week. The time spent there, for the most part and for a great number of students, was found insufficient to have any pronounced beneficial effects and was even deemed a total loss. Boredom, vandalism, problems in discipline, breakage, and poor or slow servicing of equipment made efficient operation extremely difficult and led to teacher and student frustration.

A change in scheduling permitted students to go to lab twice a week for half sessions. The normal 47-minute school period was thus divided:

$\begin{array}{lr}\text { passing time } & 3 \text { minutes } \\ \text { lab session } & 20 \text { minutes } \\ \text { passing time } & 4 \text { minutes } \\ \text { lab session } & 20 \text { minutes. }\end{array}$

This was a great improvement over the previous schedule and performance but, though it reduced the problem it did not solve it to our satisfaction.

\section{INTER-RELATIONSHIP BETWEEN CLASSROOM AND LABORA- TORY}

Scheduling, however, constituted only one phase of the problem. There was urgent need to establish a direct relationship between classroom teaching and laboratory learning. It is well known that some students learn rapidly and become bored with too much repitition - quite needless for them -, while others, though they repeat drills ad nauseam seem not to absorb the material let alone retain it. Besides, students who could profit from much repetition do not necessarily experience difficulty with the same drill. Yet, in spite of their level of achievement (or lack of it), all students participate as a group in the same exercise. Thus the goals set by teachers or by the course of study could not be realized at all levels.

It became obvious to us in Darien that better methods for large group, small group and individualized instruction had to be devised.*

\footnotetext{
* See article on A Cooperative French Program: A New Approach. published in the May, 1969 issue of Foreign Language Annals.
} 
The installation of electronic loops in every foreign language classroom offered some assistance. The teacher could divide the class into two groups and instruct one while the other group, with the help of wireless headsets could do independent work - remedial or advanced. This "dual" responsibility, however, required teachers to spend more time in the preparation of lessons and materials for, in essence, they were teaching two classes in one.

\section{SPACE FACILITIES}

A seemingly final hope lay in an innovative approach in setting up of a RESOURCE CENTER. By reallocating available space, by changing the position of booths, and by adding a visual dimension, the old lab was converted into a "new" CENTER with minimal financial expenditures.

\section{OPERATIONAL PROCEDURES}

Changes in the disposition of electronic equipment, however, required that changes be made as well in the operational procedures of the RESOURCE CENTER. The learning process that was to take place in the CENTER had to be directly related to the student's indi. vidual needs so that his classroom performance would improve.

Taped and printed materials, records, magazines, newspapers, slides, filmstrips, and student carrels were set up. To this end it was necessary to make from four to six copies of each lesson or unit of our taped materials so that they could be made readily available at the same time to several students working independently. Foreign language teachers, too, were given brief but invaluable in-service training to help them develop a more positive attitude toward the idea of a RESOURCE CENTER with its inherent, inter-related potential.

\section{OBJECTIVES}

In order to insure clearly-defined aims and purposes, certain objectives were established. The RESOURCE /CENTER would:

1. Remain open throughout the school day.

2. Create an environment conducive to better learning in an atmosphere of disciplined relaxation.

3. Encourage students to use audio-visual materials on an independent, voluntary basis.

4. Extend classroom activities by providing specifically designed space as well as individualized help by foreign language RESOURCE CENTER teachers.

5. Interest students in the culture of other countries by offering a variety of media: slides, tapes, records, film strips, newspapers, magazines, etc. 
6. Provide a place where students could converse in the foreign language. From time to time, an opportunity would be provided for them to talk with native speakers living in our com. munity, who had expressed an interest in this aspect of the program.

Our attention was then focused on the ways in which students would use the facilities and on the ways to supervise it and offer tutorial assistance.

\section{USE OF CENTER}

1. Students could use it on an independent basis (i.e. as a library.)

2. Students could converse - in moderate tones - in the foreign language, use audio-visual materials, listen to music, etc.

3. Students could use it during "open-end" or study periods, on a voluntary basis.

4. Teachers could mandate students to report to the CENTER for definite assignments whenever students were found deficient in their classroom or homework performance.

5. After consulting the Department Chairman, teachers could allow those students with linguistic ability above the level of the class to go to the CENTER to do different or more advanced work. Thus a student who could master the week's lesson within two or three classroom sessions could avoid boredom, lack of challenge or frustration in the classroom by spending the remainder of the scheduled class time in the CENTER. (It is good to report that, at the end of the scholastic year, both teachers and students found this aspect of the program most satisfactory.)

\section{SUPERVISION}

In spite of all good intentions, there is always a certain number of students who seek to avoid responsibilities and who fail to report when asked to do so. There are also those who try to take undue ad. vantage of any system of attendance taking. To prevent possible delinquency and to discourage infringements of regulations, a strict attendance procedure was designed as follows:

1. "Open-End" students reporting to the CENTER would sign a special attendance form, recording the date, the time and subject.

2. Study Hall students would report directly from the previous class to the CENTER, sign the attendance form and fill out a special slip which the teacher, through a courier, would send back to the study hall supervisor.

3. Students, except those on "open-end" or independent study, would remain in the CENTER for the entire period. (This 
regulation was designed to discourage students from milling in the corridors or leaving the building.)

4. Foreign language teachers sending students to the CENTER while their classes were in session, would issue a special pass.

5. Students would request all materials, except newspapers and magazines, from supervising teachers or student aides assigned to the CENTER. Upon leaving, students would return materials to same.

Teachers were asked to check the "sign-in" forms periodically in order to:

1. Verify which students used the CENTER and how often they used it.

2. Determine whether or not the use of the CENTER was a factor in the improvement - if any - of the student's classroom performance.

3. Verify whether those students whom they had requested to report to the CENTER had actually done so.

\section{TEACHER RELEASE-TIME AND TUTORLAL ASSISTANCE}

A significant innovation and an indispensable element of the program was the availability of foreign language teachers for tutorial assistance. Without exception the entire foreign language staff had agreed unreservedly to perform this service (which enhanced their role as teachers and professionals) if they could be released from unsavory supervisory study hall duties.

It was very obvious from the start that the CENTER could not be successfully operated without this provision. Accordingly we explained our situation to the principal, who was most understanding. He agreed to excuse foreign language teachers from study hall duties so that they could supervise the CENTER and at the same time be available to students for tutorial assistance.

Pedagogically and psychologically this proved to be a step in the right direction for students could now obtain the help of a teacher other than their own during the course of the day. This simply meant that they did not have to wait until after school hours for assistance. Teacher's name, subject area and time available were accordingly posted on the door.

\section{PROVISION FOR VISUAL MATERIALS EMPHASIZING CUL- TURAL ASPECTS}

The basic approach to foreign language teaching in Darien High School has for its primary goal the communication of ideas. These ideas express or reflect our interest in the human and cultural aspects of foreign people. We would like students to discover the way in which other people think and why they think that way. This dis- 


\section{A Step Forward}

covery will teach them that people in other countries have developed along different lines and that therefore we must not interpret their actions, attitudes and reasoning according to our own standards and patterns.

In this respect we share Prof. Stephen A. Freeman's concern that "in our desire for perfection of structure, through rigidly controlled repetitive exercises, pattern practice and substitute drills all of them excellent progress in technique - the human content, the challenge of worthwhile ideas, is being squeezed out. There is real danger that we are automating the vehicle, reducing it to such a limited range that we are forgetting to say anything worth saying. This results inevitably in diminishing the motivation of the pupil, discouraging his initiative in class, and his natural urge to share something."*

Student carrels were provided for individual audio-visual viewing. Slides and film strips with accompanying synchronized commentaries in the foreign language stressing art, music, literature, geography and other cultural aspects became a permanent feature of the CENTER.

In Darien High School we place much importance to the cultural phase of the language program; we encourage students to take advantage of foreign art exhibits, lectures, in addition to attending foreign plays, motion pictures and restaurants. But the involvement of our student in an "intellectual-cultural" experience in the RESOURCE CENTER has been the most gratifying of all.

\section{READING}

Reading at all levels is of paramount importance, for reading constitutes a major link between classroom and outside work, between oral and written work. It makes students think beyond the familiar, simplified, controlled passages. Moreover, there are students who are highly motivated by reading and who can thus acquire a knowledge of the foreign language through extensive reading.

Besides recorded text-book materials, the CENTER has a limited number of programmed readers with accompanying tapes. These materials have been designed to improve not only the intonation patterns but the reading speed as well. We have placed at the disposal of students certain reviews and periodicals which cater to the specific interests of teen-agers: TOP (in French), for example.

"Stephen A. Freeman, Let Us Build Bridges, an address given at the 15th meeting of the Northeast Conference on the teaching of Foreign Languages, N. Y. C., 5 April, 1968, pp. 5-6. 
The RESOURCE CENTER, which was opened officially on September 29, 1969 was closed June 5th. The following general data and reactions have been compiled:

Total student enrollment in our three-year high school taking modern foreign languages:

Number of students who used the CENTER (This figure does not include regularly scheduled classes for testing purposes.)

Number of periods per day

Number of days CENTER remained open

Number of students attending per daily period $\quad 68$

Number of students attending per period (annual basis) $\quad 1,457$

\section{TEACHER REACTION}

An over-all evaluation at the end of the first year resulted in the following positive responses:*

1. There has been little or no vandalism.

2. Equipment has required minimal maintenance.

3. Many students have consistently sought extra help and seem to have had a real sense of appreciation for the teacher's efforts and guidance.

4. The problem of boredom has been eliminated.

5. Students have worked within an atmosphere of "disciplined relaxation." There are no problems in discipline.

6. Effective reinforcement seems to have taken place in those areas in which the student has been weak.

7. Being relieved from unpleasant, unacademic duties (i.e. release time) has been a blessing.

8. Teachers have made better use of their time by teaching, by being in closer contact with students, and have thereby become more aware of general attitudes.

9. Greater individual use of visual materials has given students deeper insight into the culture of other people.

10. The "decentralization" and expansion of the original lab within the same physical facilities has produced variety and pleasure; it has presented attractive conditions conducive to better learning.

\section{STUDENT REACTIONS}

1. There has been much self-motivation.

2. They have been able to drill as often as necessary in a specific area without feeling that the teacher is becoming impatient or that other students are being "held back."

*In both teacher and student reactions no attempt has been made to establish any order of importance in the statements. 


\section{A Step Forward}

3. They have not experienced boredom.

4. They have had the opportunity to do remedial or advanced work at their own pace.

5. The atmosphere has been pleasant.

6. Tutorial assistance has been "just great."

7. Carrels are wonderful; there has been fine opportunity to see what the foreign country looks like and to learn about its culture. Listening to the accompanying tapes has made the viewing much more interesting. It has been a real experience and has made them want to visit those places.

8. They have enjoyed listening to music records.

9. It has been a "good place to go to" as a substitute for study periods.

10. It has been a good place to prepare special reports or projects.

\section{CONCLUSION}

Among the perspectives of foreign language teaching that merit emphasis, one of them is certainly that the issue of foreign language LABORATORIES and RESOURCE CENTERS can not be adequately viewed in anything less than its relationship to the total learning situation. Attempts to see it from the point of view of a special but separate unit - as has often been the case in the past - has culminated in gross dissatisfaction. The fact of the matter is that there has been a wide gap between our knowledge of what labs can do and our practical application of that knowledge. What must be done is to bring together in an integrated way our knowledge of the learning process in the classroom and transfer it, with the help of proper and suitable methods and materials, to the RESOURCE CENTER so that it will be both reasonable and useful.

Modification of our original foreign language lab into a RESOURCE CENTER has proved to be a step in the right direction. As a result of this small but significant innovation, we, in the Foreign Language Department, are confident that, given wider scope and vision, the RESOURCE CENTER can play an invaluable role in the acquisition of a modern foreign language and in the better understanding of other people.

About the Author: Dr. Rollo is Chairman of the Department of Foreign Languages, Darien High School, Darien, Connecticutt. 